\title{
Dietary linseed oil increases trans-10,cis-15 18:2 in caprine milk fat
}

\author{
P. Gómez-Cortés, ${ }^{*}$ A. Cívico,† M. A. de la Fuente, ${ }^{*}$ M. Juárez, ${ }^{*}$ N. Núñez Sánchez,† F. Peña Blanco,† \\ and A. L. Martínez Marín† ${ }^{1}$ \\ *Instituto de Investigación en Ciencias de la Alimentación (CSIC-UAM), Universidad Autónoma de Madrid, Nicolás Cabrera 9, 28049 Madrid, \\ Spain \\ †Departamento de Producción Animal, Universidad de Córdoba, Ctra. Madrid-Cádiz km 396, 14071 Córdoba, Spain
}

\section{ABSTRACT}

Trans-10,cis-15 18:2 has been recently detected and characterized in digestive contents and meat and adipose tissue of ruminants, but its presence in milk and dairy products is hardly known. The aim of this study was to quantify trans-10,cis-15 18:2 in milk fat, better understand its metabolic origin, and help to elucidate the mechanisms of rumen biohydrogenation when the diet composition might affect ruminal environment. To address these objectives, 16 dairy goats were allocated to 2 simultaneous experiments (2 groups of goats and 2 treatments in each experiment). Experimental treatments consisted of basal diets with the same forageto-concentrate ratio $(33 / 67)$ and 2 starch-to-nonforage neutral detergent fiber (NDF) ratios (0.8 and 3.1), which were supplemented or not with $30 \mathrm{~g} / \mathrm{d}$ of linseed oil for $25 \mathrm{~d}$ in a crossover design. Trans-10, cis-15 18:2 contents in milk fat were determined by gas chromatography fitted with an extremely polar capillary column (SLB-IL111). Levels of trans-10,cis-15 18:2 in individual milk fat samples ranged from 0 to $0.2 \%$ of total fatty acids, and its content in milk fat increased 8 fold due to linseed oil supplementation, substantiating the predominant role of $\alpha$-linolenic acid in its formation. The trans-10,cis-15 18:2 levels in milk fat were similar in both experiments, despite the fact starchto-nonforage NDF ratio of their respective basal diets greatly differed. In conclusion, trans-10,cis-15 18:2 was clearly related to linseed oil supplementation, and its increase in milk fat was comparable when the basal diets were rich in either nonforage NDF or starch. Key words: milk fat, fatty acid, linseed oil, $\alpha$-linolenic acid

Received December 8, 2016.

Accepted February 26, 2017.

${ }^{1}$ Corresponding author: pa1martm@uco.es

\section{INTRODUCTION}

Milk fatty acid (FA) profile depends upon digestive processes and mammary gland lipid metabolism. Partial biohydrogenation and isomerization of PUFA by rumen bacteria generate a multiplicity of 18-carbon FA with different degree of unsaturation as well as positional and geometrical configurations, which are not completely characterized. The main route of $\alpha$-linolenic acid biohydrogenation in the rumen first involves the isomerization of the cis-12 double bond to trans-11 (Figure 1). The obtained cis-9,trans-11,cis-15 18:3 is then hydrogenated to trans-11,cis-15 18:2, and finally to trans-11 18:1 (Harfoot and Hazlewood, 1997). Griinari and Bauman (1999) hypothesized that an altered rumen environment induced by feeding low-fiber diets could cause a shift in the biohydrogenation pathways of $\alpha$-linolenic acid, favoring the isomerization of the cis-9 double bond to trans-10. In this way, trans-10 18:1 could originate not only from cis-9,cis-12 18:2 via trans-10,cis-12 18:2, but also from $\alpha$-linolenic acid via trans-10,cis-12,cis-15 18:3 and trans-10,cis-15 18:2 (Figure 1).

Alves and Bessa (2014) first identified and characterized trans-10,cis-15 18:2 in digestive contents and meat from lambs fed a diet supplemented with linseed oil. More recently, Honkanen et al. (2016) found trans-10,cis-15 18:2, among other PUFA, as a result of $\alpha$-linolenic acid metabolism during incubations with strained bovine rumen contents. However, evidence of the presence of that 18:2 isomer in milk and dairy products and quantification of its response to diet supplementation with $\alpha$-linolenic acid sources is scant (De la Fuente et al., 2015; Manso et al., 2016).

In the present study, our first objective was to take advantage of the selectivity of the new ionic liquid capillary column of extreme polarity (SLB-IL111; Supelco, Bellefonte, PA) to confirm and quantify the presence of trans-10,cis-15 18:2 in milk fat. Second, to explore its metabolic origin, rations that differed in starch-tononforage NDF ratio and were supplemented or not with linseed oil were assayed in dairy goats. 


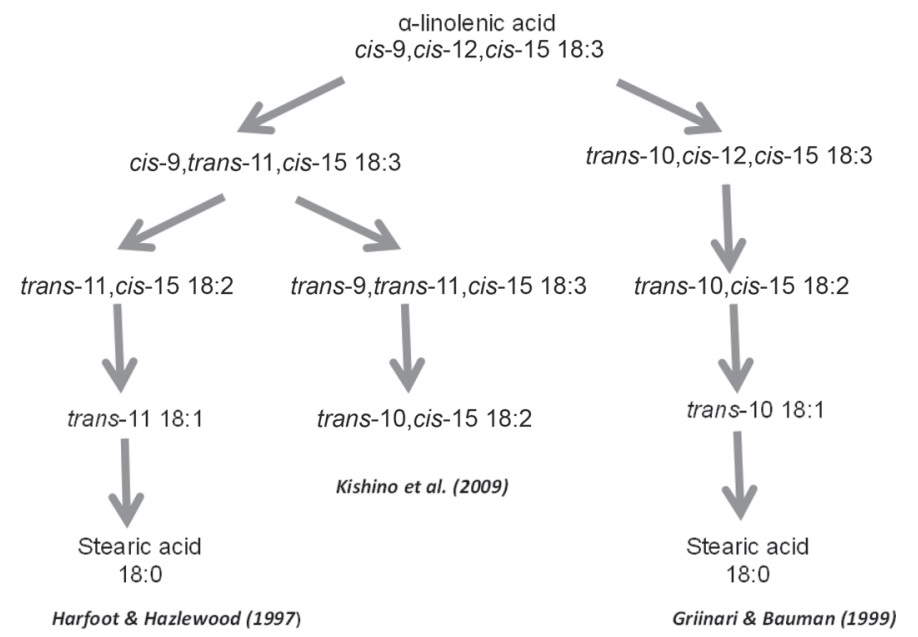

Figure 1. Pathways of ruminal biohydrogenation of $\alpha$-linolenic acid postulated by Harfoot and Hazlewood (1997), Griinari and Bauman (1999), and Kishino et al. (2009).

\section{MATERIALS AND METHODS}

The present research was carried out at the University of Córdoba facilities in accordance with the EU Directive 2010/63/EU (EC, 2010) for animal studies. Sixteen Malagueña goats (initially $118 \pm 16$ DIM and $52.9 \pm$ $3.7 \mathrm{~kg}$ of BW) were allocated to 2 experiments ( 2 treatments each), conducted simultaneously, in a crossover design with 4 animals per treatment and 2 experimental periods of $25 \mathrm{~d}$. The goats were selected from a commercial farm and blocked by BW and milk production (4 animals in each block). Within each block the animals were randomly assigned to the treatments so all the blocks were represented in all the treatments. During the study, the goats were placed in individual cages of $1.0 \times 1.4 \mathrm{~m}$ with slatted floors and individual water and feeding troughs. In both experiments, the basal diet consisted of alfalfa hay and a pelleted concentrate fed separately, had the same forage-to-concentrate ratio (33:67), and was supplemented or not with $30 \mathrm{~g} / \mathrm{d}$ of linseed oil (Table 1). In experiment 1 , the concentrate consisted of soybean hulls, barley, maize, and soybean meal, whereas the concentrate of experiment 2 did not include soybean hulls, which were replaced by equal parts of barley and maize. As a result, the starch-tononforage NDF ratio of the diet was 0.8 in experiment 1 and raised to 3.1 in experiment 2. Thus, 2 treatments were tested in each experiment: a basal diet with high nonforage NDF content $(\mathbf{F})$ and the same diet plus linseed oil $(\mathbf{F}+\mathbf{L O})$ in experiment 1 , and a basal diet with high starch content $(\mathbf{S})$ and the same diet plus linseed oil $(\mathbf{S}+\mathbf{L O})$ in experiment 2 . The diet was offered in 2 equal meals at 0930 and 1730 h. Voluntary feed intake was recorded daily for each animal and was calculated as the difference between feed offered and orts. Water was provided ad libitum. The goats were machine milked and stripped out by hand once a day at $0830 \mathrm{~h}$. Individual milk samples were collected on the last day of each experimental period and stored at $-20^{\circ} \mathrm{C}$ until analysis.

Additionally, to collect further information on the trans-10, cis-15 18:2 metabolic origin, bulk milk samples (100 animals per tank) from a previous trial were reanalyzed (Gómez-Cortés et al., 2009). In Gómez-Cortés et al. (2009), 300 Manchega ewes receiving a 60:40 forage:concentrate diet were divided into 3 groups. One group was supplemented with 6\% (DM basis) of extruded linseed (LEL), other group was supplemented with $12 \%$ (DM basis) of extruded linseed (HEL), and the last group (CON) was fed without linseed supplementation. Milk samples were collected at $0,7,14,28$, 45 , and $60 \mathrm{~d}$ following supplementation. Housing, management, and diet composition are described in detail in Gómez-Cortés et al. (2009).

Milk fat extraction and derivatization of FA to FAME were carried out according to Bodas et al. (2010). Gas chromatography with 2 different columns was used to determine the content of selected FAME in accordance with the method proposed by De la Fuente et al. (2015). An Agilent model 6890 N Network Gas Chromatograph (Palo Alto, CA) equipped with auto-injector and flame ionization detector, fitted with a CP-Sil 88 fused silica capillary column $(100 \mathrm{~m} \times 0.25 \mathrm{~mm}$ i.d., Varian, Middelburg, the Netherlands) as well as an Agilent gas chromatograph, model 7820A GC System equipped with auto-injector and flame ionization detector, fitted with a SLB-IL111 capillary column $(100 \mathrm{~m} \times 0.25$ $\mathrm{mm}$ i.d., Supelco) were used. Fatty acids were identified based on retention time and elution order as described by Alves and Bessa (2014).

We used SAS University Edition 3.4 (SAS Institute, Cary, NC) in the statistical analyses. Milk fat composition data from each experiment were analyzed with the MIXED procedure, according to the model:

$$
\mathrm{Y}_{i j k l m}=\mu+\mathrm{T}_{i}+\mathrm{P}_{j}+\mathrm{S}_{k}+\mathrm{G}_{l}(\mathrm{~S})_{k}+\mathrm{e}_{i j k l m},
$$

where $\mathrm{Y}_{i j k l m}=$ dependent variable, $\mu=$ overall mean, $\mathrm{T}_{i}$ = fixed effect of treatment ( $i=1$ to 2$), \mathrm{P}_{j}=$ fixed effect of period ( $j=1$ to 2$), \mathrm{S}_{k}=$ fixed effect of sequence $(k$ $=1$ to 2$), \mathrm{G}_{l}(\mathrm{~S})_{k}=$ random effect of animal $(l=1$ to 4$)$ nested within sequence $k, \mathrm{e}_{i j k l m}=$ random residual. The CORR procedure was used to investigate the relationship between selected FA. Significant differences were declared at $P<0.05$. 
Table 1. Ingredients and chemical composition of the diets assayed

\begin{tabular}{|c|c|c|c|c|}
\hline \multirow[b]{2}{*}{ Item } & \multicolumn{2}{|c|}{ Experiment 1} & \multicolumn{2}{|c|}{ Experiment 2} \\
\hline & $\mathrm{F}^{1}$ & $\mathrm{~F}+\mathrm{LO}^{1}$ & $S^{1}$ & $\mathrm{~S}+\mathrm{LO}^{1}$ \\
\hline \multicolumn{5}{|l|}{$\operatorname{Diet}(\mathrm{g} / \mathrm{d})$} \\
\hline Alfalfa hay & 600 & 600 & 600 & 600 \\
\hline Pelleted concentrate $^{2}$ & 1,200 & 1,200 & 1,200 & 1,200 \\
\hline Linseed $\mathrm{oil}^{3}$ & - & 30 & - & 30 \\
\hline \multicolumn{5}{|l|}{ Chemical composition } \\
\hline $\mathrm{DM}(\%)$ & 89.5 & 90.0 & 89.2 & 89.7 \\
\hline Ash $(\% \mathrm{DM})$ & 7.3 & 7.2 & 7.0 & 6.8 \\
\hline $\mathrm{CP}(\% \mathrm{DM})$ & 18.1 & 18.0 & 18.2 & 17.8 \\
\hline NDF (\% DM) & 40.7 & 40.4 & 27.5 & 27.7 \\
\hline Nonforage NDF (\% DM) & 23.5 & 23.2 & 10.3 & 10.5 \\
\hline Starch $(\% \mathrm{DM})$ & 19.7 & 18.3 & 33.6 & 32.1 \\
\hline Fat by acid hydrolysis (\% DM) & 2.1 & 3.9 & 2.9 & 4.4 \\
\hline \multicolumn{5}{|l|}{ Fatty acids supplied $(\mathrm{g} / \mathrm{d})$} \\
\hline $\mathrm{C} 16: 0$ & 4.6 & 6.3 & 5.0 & 6.7 \\
\hline C18:0 & 1.0 & 2.2 & 0.8 & 2.0 \\
\hline cis-9 C18:1 & 5.3 & 10.6 & 5.5 & 10.8 \\
\hline cis-9,cis-12 C18:2 & 13.7 & 18.4 & 14.3 & 19.0 \\
\hline cis-9,cis-12,cis-15 C18:3 & 3.8 & 17.8 & 3.4 & 17.4 \\
\hline
\end{tabular}

${ }^{1} \mathrm{~F}=$ high nonforage NDF; $\mathrm{F}+\mathrm{LO}=$ high nonforage NDF plus linseed oil; $\mathrm{S}=$ high starch; $\mathrm{S}+\mathrm{LO}=$ high starch plus linseed oil.

${ }^{2}$ Composition (g/kg, as fed): soybean hulls, 356.0; maize, 178.0; barley, 178.0; and soybean meal, 250.0, in the F concentrate; and maize, 356.0; barley, 356.0; and soybean meal, 250.0, in the S concentrate. Both concentrates included (g/kg, as fed): vitamin and mineral premix (Trouwmix M-3020, Trouw Nutrition, Madrid, Spain), 30.0; binder (Exal; Tolsa SA, Madrid, Spain), 7.0; and antioxidant (Luctanox; Lucta SA, Barcelona, Spain), 1.0 .

${ }^{3}$ The oil was included in the respective concentrate, during mixing before pelleting.

\section{RESULTS AND DISCUSSION}

Feed intake, milk yield, fat content, and protein content were in the ranges $1,645 \pm 168$ to $1,722 \pm 117 \mathrm{~g} / \mathrm{d}$, $1,227 \pm 376$ to $1,552 \pm 592 \mathrm{~g} / \mathrm{d}, 3.83 \pm 0.87$ to $4.89 \pm$ $0.41 \%$, and $3.49 \pm 0.62$ to $3.61 \pm 0.13 \%$, respectively. Figure 2 depicts partial GC chromatograms showing the 18:2 region of milk FAME from goats fed the different diets $(\mathrm{F}, \mathrm{F}+\mathrm{LO}, \mathrm{S}$, and $\mathrm{S}+\mathrm{LO})$. In contrast to $\mathrm{CP}-\mathrm{Sil}$ 88 column analysis, where trans-11,cis-15 and trans10,cis-15 18:2 isomers co-eluted in the same peak, the new ionic liquid stationary phase of extreme polarity (SLB-IL111 capillary column) eluted separately both FA, thus permitting an easy quantification. In both experiments, trans-10,cis-15 18:2 levels were 8-fold higher in the milk from the linseed oil supplemented treatments compared with their respective controls (Table 2, Figure 2). It is noteworthy that the observed increase occurred regardless of the great difference in the starch to nonforage NDF of the basal diets between experiments. Most of the individual goat milk fat samples contained trans-10,cis-15 18:2, but in low or very low amounts. The highest content did not exceed $0.2 \%$ of total FA. Alves and Bessa (2014) first detected FA in digestive contents and meat from lambs, and Turner et al. (2015) determined its presence in bovine adipose tissue, but no quantitative information was given. Bravo-
Lamas et al. (2016) recently reported the contents of trans-10,cis-15 18:2 in lamb subcutaneous fat, providing values in the same range as those observed in the milk fat of the current study.

Table 2 shows the effects of the experimental diets fed to the goats on the milk fat contents of selected FA that are related to the metabolism of $\alpha$-linolenic and linoleic acids in the rumen. Fatty acids from established ruminal biohydrogenation pathways of $\alpha$-linolenic acid, such as cis-9,trans-11,cis-15 18:3 and trans-11,cis-15 18:2, significantly increased in the $\mathrm{F}+\mathrm{LO}$ and $\mathrm{S}+\mathrm{LO}$ treatments compared with their respective controls. In contrast, the observed contents were similar between the analogous treatments of both experiments ( $\mathrm{F}$ vs. $\mathrm{S}$ and $\mathrm{F}+\mathrm{LO}$ vs. S+LO). Trans-10,cis-15 18:2 followed the same pattern of the ruminal biohydrogenation products of $\alpha$-linolenic acid, which would indicate that $\alpha$-linolenic acid supplied by linseed oil was indispensable to generate trans-10,cis-15 18:2 in the rumen and to increase its contents in milk fat. Furthermore, trans10,cis-15 18:2 was well correlated with $\alpha$-linolenic acid in milk fats $(\mathrm{r}=0.79 ; P<0.001)$, supporting the idea that both PUFA are closely linked. Our results are in line with those of Honkanen et al. (2016), who related trans-10,cis-15 18:2 with $\alpha$-linolenic acid metabolism by rumen microbes in vitro, as well as those of Alves and Bessa (2014) and Turner et al. (2015), who found 
Table 2. Contents ( $\mathrm{g} / 100 \mathrm{~g}$ of FAME) of selected fatty acids in the milk fat of dairy goats fed 2 basal diets, in separate experiments, supplemented or not with linseed oil

\begin{tabular}{|c|c|c|c|c|c|c|c|c|}
\hline \multirow[b]{2}{*}{ Item } & \multicolumn{4}{|c|}{ Experiment $1^{1}$} & \multicolumn{4}{|c|}{ Experiment $2^{1}$} \\
\hline & $\mathrm{F}$ & $\mathrm{F}+\mathrm{LO}$ & SEM & $P$-value & $\mathrm{S}$ & $\mathrm{S}+\mathrm{LO}$ & SEM & $P$-value \\
\hline trans-11 18:1 & 1.15 & 3.26 & 0.299 & $<0.001$ & 1.87 & 3.25 & 0.223 & $<0.001$ \\
\hline trans-10, cis-15 18:2 & 0.01 & 0.08 & 0.012 & $<0.05$ & 0.01 & 0.08 & 0.012 & $<0.01$ \\
\hline trans-11, cis-15 18:2 & 0.05 & 0.67 & 0.084 & $<0.001$ & 0.09 & 0.55 & 0.065 & $<0.001$ \\
\hline trans-10,cis-12 18:2 & 0.01 & 0.01 & 0.001 & 0.35 & 0.01 & 0.01 & 0.001 & 0.92 \\
\hline trans-10 18:1/trans-11 18:1 & 0.29 & 0.14 & 0.022 & $<0.001$ & 0.29 & 0.17 & 0.031 & 0.06 \\
\hline trans-10 18:1/trans-10,cis-12 18:2 & 142 & 207 & 28.1 & 0.27 & 177 & 178 & 22.6 & 0.97 \\
\hline trans-10 18:1/trans-10,cis-15 18:2 & 29 & 7 & 3.0 & $<0.05$ & 78 & 8 & 13.5 & $<0.001$ \\
\hline
\end{tabular}

${ }^{1} \mathrm{~F}=$ high nonforage NDF; F+LO = high nonforage NDF plus linseed oil; $\mathrm{S}=$ high starch; $\mathrm{S}+\mathrm{LO}=$ high starch plus linseed oil.

trans-10,cis-15 18:2 in ruminant tissues from animals fed linseed oil and linseed supplemented diets, respectively.

On the other hand, the immediate precursor of trans10,cis-15 18:2 in milk would be somewhat uncertain. We did not detect its putative precursor trans-10, cis12,cis-15 18:3 in any of the samples analyzed, and neither did Alves and Bessa (2014) in their study. However, Honkanen et al. (2016) detected trans-10,cis-12,cis-15
18:3 positional isomers in incubations of $\alpha$-linolenic acid with strained bovine rumen contents but, at such low amounts, that no conclusions could be drawn about the possible mechanisms involved. Kishino et al. (2009) found trans-10,cis-15 18:2 in cells of Lactobacillus plantarum after incubation with $\alpha$-linolenic acid. Those authors suggested a metabolic pathway in which trans-10,cis-15 18:2 is formed from $\alpha$-linolenic acid via conjugated cis-9,trans-11,cis-15 18:3 and trans-9,trans-

\section{cis-9,cis-12 18:2}

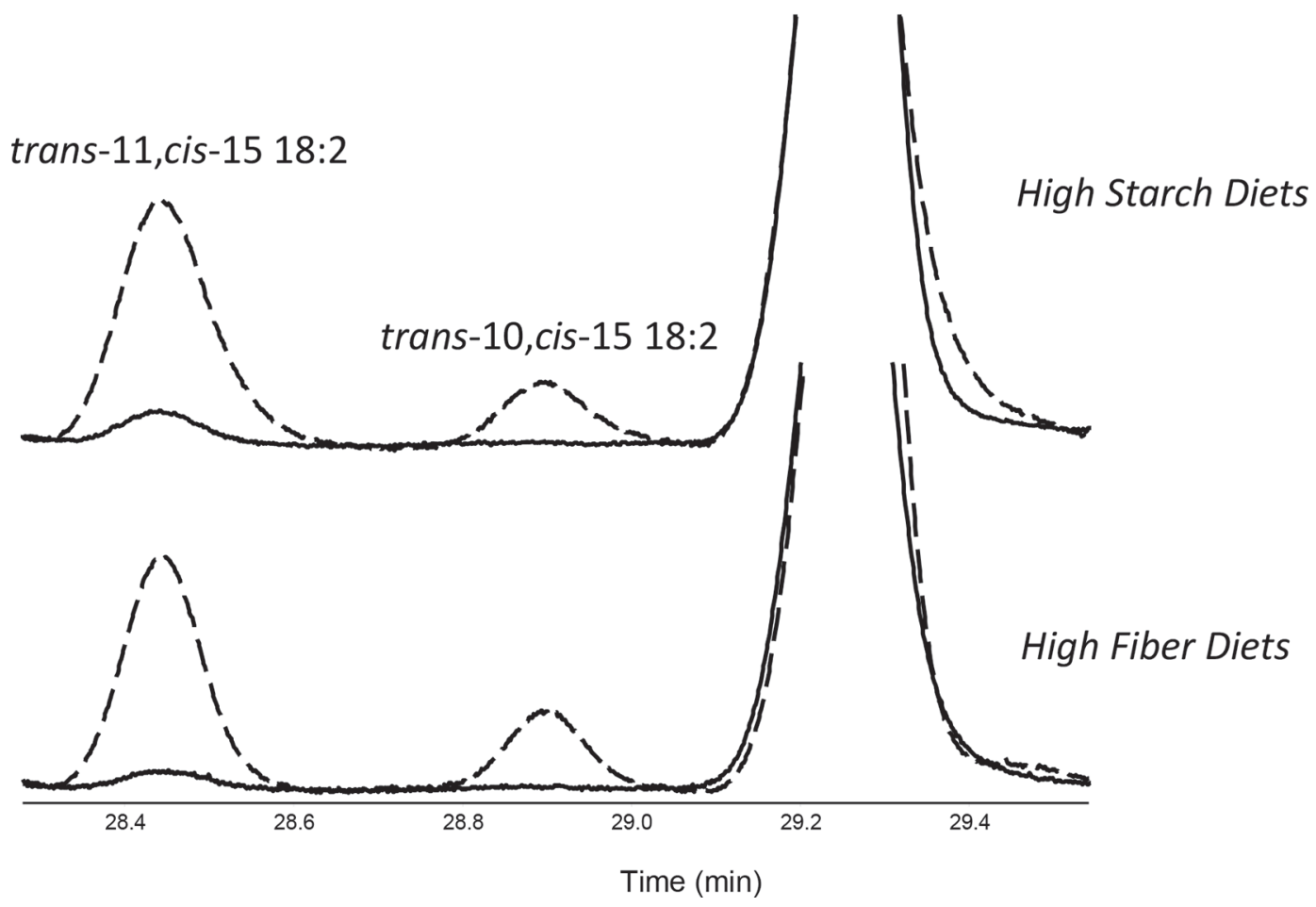

Figure 2. Partial GC chromatograms of the 18:2 region using an extremely polar capillary column (SLB-IL111, Supelco, Bellefonte, PA). The analyzed milk samples are from goats fed high-starch (top) or high-fiber diets (bottom) with (- - -) or without (-) linseed oil supplementation $(30 \mathrm{~g} / \mathrm{d})$. 
11,cis-15 18:3, without the production of trans-10 18:1 (Figure 1). In the study of Honkanen et al. (2016), both 18:3 isomers, mainly cis-9,trans-11,cis-15, were detected during the first hour of incubation and their amounts declined thereafter. In the present study, cis-9,trans11,cis-15 18:3 was significantly increased in the milk fat from goats fed the linseed oil supplemented diets (Table 2), but trans-9,trans-11,cis-15 18:3 was not detected. The lack of this intermediate in milk could be justified by its low production in the rumen, as L. plantarum is not recognized as being a predominant microorganism in the ruminal ecosystem (Lourenço et al., 2010).

It is noteworthy that linseed oil supplementation only raised the content of trans-10 18:1 in experiment 1 (high-fiber diets), but the value reached in the $\mathrm{F}+\mathrm{LO}$ treatment was not as high as those observed in any of the treatments of experiment 2 (high-starch diets; Table 2). On the contrary, the observed increase of trans10,cis-15 18:2 due to linseed oil in the diet was similar in both experiments. These results would indicate that a high starch intake favored the production of trans-10 18:1 in the rumen, but had little relevance to generate trans-10,cis-15 18:2. In this regard, it has been stated that a high proportion of starch in the diet contributes to modify the ruminal biohydrogenation pathways, with the largest trans-10 18:1 shift being associated with the abundance of linoleic acid, but not $\alpha$-linolenic acid, in the rations (Zened et al., 2011, 2013). Furthermore, the trans-10 18:1-to-trans-10,cis-15 18:2 ratio in milk fat significantly decreased when linseed oil was included in both experiments (Table 2), thus indicating that an increase of the substrate, trans-10,cis-15 18:2, did not cause a parallel rising in milk trans-10 18:1 levels and that the formation of trans-10 18:1 from trans-10,cis-15 18:2 in the rumen would not be remarkable. In comparison, the trans-10 18:1 to trans-10,cis-12 18:2 ratio in milk fat was not modified in the $\mathrm{F}+\mathrm{LO}$ and $\mathrm{S}+\mathrm{LO}$ treatments compared with the $\mathrm{F}$ and $\mathrm{S}$ treatments, respectively, which would reveal that their metabolic relationship could be relatively independent of the inclusion of linseed oil in goat diets (Martínez Marín et al., 2015).

To confirm the role of $\alpha$-linolenic acid in the metabolic origin of trans-10,cis-15 18:2, sheep bulk milk fats, sampled over time in a previous trial (Gómez-Cortés et al., 2009), were reanalyzed by GC using the SLBIL111 column. The obtained data did not allow us to investigate statistical differences, but the results are of interest from a qualitative point of view. The LEL and HEL diets sharply increased the trans-10,cis-15 18:2 levels in milk fat during the first week of supplementation (from $0.01 \%$ of total FAME at d 0 in both treatments to 0.05 and $0.07 \%$ of total FAME in the LEL and HEL treatments, respectively) and did not decrease from that level thereafter. The highest level $(0.10 \%$ of total FAME) was reached at the end of the monitoring period in the HEL treatment. Trans-10, cis-15 18:2 contents in milk fat showed a high correlation with those of $\alpha$-linolenic acid $(\mathrm{r}=0.99, P<0.001)$, indicating once more that both FA are closely related. Moreover, the trans-10 18:1-to-trans-10,cis-15 18:2 ratio in milk fat remained relatively unchanged during the experimental period in the CON treatment $(44 \pm 11)$, whereas it was substantially lower from the first week onwards in the LEL and HEL treatments $(9 \pm 1$ and $6 \pm 1$ vs. initial values of 32 and 36 , respectively). These observations indicate that dietary linseed had a considerable influence on the presence of trans-10,cis-15 18:2 in the milk fat of the ewes, but did not entail an increase of trans-10 18:1, in agreement with previously mentioned results. Therefore, under the experimental conditions assayed, trans-10 18:1 would not be formed from trans10, cis-15 18:2 in goats and ewes.

Overall, this research confirms the predominant role of $\alpha$-linolenic acid as precursor of trans-10,cis-15 18:2 in milk fat and dismisses trans-10,cis-15 18:2 as precursor of trans-10 18:1, at least under the conditions assayed. The present investigation did not allow us to elucidate the routes explaining the conversion of $\alpha$-linolenic acid to trans-10,cis-15 18:2 and further research needs to be done, as minor intermediates not present in milk or still unknown may play a relevant role.

\section{ACKNOWLEDGMENTS}

This work was supported by the Ministerio de Economía y Competitividad (Project AGL2016-75159C2-2-R, Madrid, Spain). Pilar Gómez-Cortés was subsidized with a Juan de la Cierva research contract from the Ministerio de Economía y Competitividad. The authors thank M. V. Rodríguez Pino (CIAL, Madrid, Spain), and I. Andújar Ramírez and J. J. Pérez Hernández (both from Universidad de Córdoba, Córdoba, Spain) for their valuable technical assistance. Authors are indebted to A. Bach (IRTA, Gerona, Spain) and P. Luna (UAM, Madrid, Spain) for their support on the sheep trial.

\section{REFERENCES}

Alves, S. P., and R. J. B. Bessa. 2014. The trans-10,cis-15 18:2: A missing intermediate of trans-10 shifted rumen biohydrogenation pathway? Lipids 49:527-541.

Bodas, R., T. Manso, A. R. Mantecón, M. Juárez, M. A. de la Fuente, and P. Gómez-Cortés. 2010. Comparison of the fatty acid profile in cheeses from ewes fed diets supplemented with different plant oils. J. Agric. Food Chem. 58:10493-10502.

Bravo-Lamas, L., L. J. R. Barron, J. K. G. Kramer, I. Etaio, and N. Aldai. 2016. Characterization of the fatty acid composition of 
lamb commercially available in northern Spain: Emphasis on the trans-18: 1 and CLA content and profile. Meat Sci. 117:108-116.

De la Fuente, M. A., V. Rodríguez-Pino, and M. Juárez. 2015. Use of extremely polar 100-m column in combination with cyanoalkyl polysiloxane column to complement the study of milk fats with different fatty acid profiles. Int. Dairy J. 47:52-63.

EC (European Commission). 2010. Directive 2010/63/EU of the European Parliament and of the Council of 22 September 2010 on the protection of animals used for scientific purposes. Official J. EU 276:33-79.

Gómez-Cortés, P., A. Bach, P. Luna, M. Juárez, and M. A. de la Fuente. 2009. Extruded linseed on ewes rations improves omega-3 fatty acids and conjugated linoleic acid contents in cheese and milk fat. J. Dairy Sci. 92:4122-4134.

Griinari, J. M., and D. E. Bauman. 1999. Biosynthesis of conjugated linoleic acid and its incorporation into meat and milk in ruminants. Pages 180-200 in Advances in Conjugated Linoleic Acid Research. Vol. 1. M. P. Yurawecz, M. M. Mossoba, J. K. G. Kramer, M. W. Pariza, and G. J. Nelson, ed. AOCS Press, Champaign, IL.

Harfoot, C. G., and G. P. Hazlewood. 1997. Lipid metabolism in the rumen. Pages 382-426 in The Rumen Microbial Ecosystem. P. N. Hobson and C. S. Stewart, ed. Blackie Academic \& Professional, New York, NY.

Honkanen, A. M., H. Leskinen, V. Toivonen, N. McKein, R. J. Wallace, and K. J. Shingfield. 2016. Metabolism of $\alpha$-linolenic acid during incubations with strained bovine rumen contents: Products and mechanims. Br. J. Nutr. 115:2093-2105.

Kishino, S., J. Ogawa, K. Yokozeki, and S. Shimizu. 2009. Metabolic diversity in biohydrogenation of polyunsaturated fatty acids by lactic acid bacteria involving conjugated fatty acid production. Appl. Microbiol. Biotechnol. 84:87-97.

Lourenço, M., E. Ramos-Morales, and R. J. Wallace. 2010. The role of microbes in rumen lipolysis and biohydrogenation and their manipulation. Animal 4:1008-1023.

Manso, T., B. Gallardo, A. Salvá, C. Guerra-Rivas, A. R. Mantecón, P. Lavín, and M. A. de la Fuente. 2016. Influence of dietary grape pomace combined with linseed oil on fatty acid profile and milk composition. J. Dairy Sci. 99:1111-1120.

Martínez Marín, A. L., P. Gómez-Cortés, N. Núñez Sánchez, M. Juárez, A. I. Garzón Sigler, F. Peña Blanco, and M. A. de la Fuente. 2015. Associations between major fatty acids in plant oils fed to dairy goats and C18 isomers in milk fat. J. Dairy Res. 82:152-160.

Turner, T. D., W. J. Meadous, C. Mapiye, P. Vahmani, O. LópezCampos, P. Duff, D. C. Rolland, J. S. Church, and M. E. R. Dugan. 2015. Isolation of $\alpha$-linolenic acid biohydrogenation products by combined silver ion solid phase extraction and semi-preparative high performance liquid chromatography. J. Chromatogr. B Analyt. Technol. Biomed. Life Sci. 980:34-40.

Zened, A., F. Enjalbert, M. C. Nicot, and A. Troegeler-Meynadier. 2013. Starch plus sunflower oil addition to the diet of dry dairy cows results in a trans-11 to trans-10 shift of biohydrogenation. J. Dairy Sci. 96:451-459.

Zened, A., A. Troegeler-Meynadier, M. C. Nicot, S. Combes, L. Cauquil, Y. Farizon, and F. Enjalbert. 2011. Starch and oil in the donor cow diet and starch in substrate differently affect the in vitro ruminal biohydrogenation of linoleic and linolenic acids. J. Dairy Sci. 94:5634-5645. 